\title{
A Computer Game Modelling Routing in Computer Networks as Abstract Learning Material in a Blended Learning Environment
}

\author{
doi:10.3991/ijet.v4s3.1081 \\ Olaf Hallan Graven, Hallstein Asheim Hansen and Lachlan MacKinnon \\ Buskerud University College, Kongsberg, Norway
}

\begin{abstract}
We use routing in computer networks as an experiment to determine the viability of using a computer game specifically designed to incorporate abstract learning materials as part of a blended learning environment. Routing is the process of determining a data packet's path trough a network. The students participating in the experiment play a short computer game where the word is a network modelled as a labyrinth. The conclusion we draw from the experiment is that overall the students felt that they learned just as much from this as from a traditional lecture/lab, but that they enjoyed this more.
\end{abstract}

Index Terms-Blended learning, networks, games based learning.

\section{INTRODUCTION}

The experiment described here is to determine the viability of using a computer game specifically designed to incorporate abstract learning materials as part of a blended learning environment. The students first participate in a game before they are involved in a workshop focusing on the topics identified by their lecturer. The learning content in the game is designed as an abstraction of the topics the students are working with in the workshop. Our case study is the topic of routing in computer networks. The lecturer had previously identified routing as an area where the students would benefit from increased motivation, if they could be enticed to engage more with the subject matter.

The learning environment is created with no game elements other than those that are necessary to solve the quests given to the students during the game. The game can be run both as single and multi-player. We arranged a competition for the students during this experiment, and ran it as a multi-player game. This prototype was created as part of a greater experiment investigating the success of placing learning material in gaming environments. As well as considering the value of the prototype in supporting a blended learning exercise, the experiment was used to help determine whether removing all explicit game playing activities not directly linked to the learning material still makes it possible to create a game that can be engaging for the students. As part of the experimental model the students are asked whether they feel playing the game improves their knowledge, if they enjoy this form of learning, and if they find it useful.

\section{A. Blended learning}

The model used when presenting the learning material in this experiment is similar to what has become known for some as "blended learning" [1]. The effectiveness of blended learning has been examined by many others for examples see [2-4].

Blended learning is generally used to describe learning that mixes various event-based activities, including faceto-face, asynchronous and synchronous e-learning. Our model is based upon a mix of a game with abstract learning materials followed by a combination of face-to-face traditional lectures and in class discussion. The abstract learning material is as mentioned modelled as a game and is used mainly to engage the students and provide a introduction to the in class activities.

One of the arguments for blended learning is that a closer examination reveals the ability of Internet communication technology to facilitate a simultaneous independent and collaborative learning experience [2]. That is, learners can be independent, work at their own pace, time and location, and still maintain the all-important social links when learning. The way this experiment was run did not initially support this, the game however was available to use for the students including the ones not present at the initial run. The importance of revisiting material and the ability this has to encourage reflection and precision of expression is well known [5].

It is our view that the social aspects of learning are essential. Learning is not required to be done face to face in a lecture situation, but social activities are an important and significant part of the process. As Mayes puts it [6]: "Lectures are occasions where the individual is confirmed as a member of a learning community." This is the reasoning behind the class discussion as part of the class activities run just after the initial game playing.

The efforts involved in converting traditional courses into courses supported by games are considerable. The effort that has gone into creating the game presented here are however not too excessive. A games developer can create this game in a few days after the initial ideas and plan for content is finalised.

It is important in e-learning and in blended learning to go beyond the first step of just publishing material on the web so that the students have access to it in electronic format. This fist step is known as shovelware and it has been shown in research done by Khalifa [7] that learning materials are more useful for students when they incorporate some interactivity. The experiment was carried out with two equal groups of students alternating between a "shovelware" setup (a PowerPoint presentation and a Word document), and an alternate setup of properly con- 


\section{A Computer Game Modelling Routing in Computer Networks as Abstract Learning Material IN A BLENDED LEARNING ENVIRONMENT}

structed interconnected documents. The findings in the study were clear:

"The Distributed Interactive Learning Web site was found to be superior to the Distributed Passive Learning Web site in terms of both the learning process and the learning outcome". [7]

The results from the study showed that the extra work the educator puts into development of an interactive site actually pays off.

\section{LEARNING CONTENT}

In this section we give a brief introduction to routing, and link state routing in particular. Then we compare the routing process to our game, pointing out differences and similarities.

\section{A. Routing}

Routing in a packet switching network [8], such as the Internet, is the process of determining the transmission path of a data packet from some source to some destination. In general we separate between routers, computers that forwards packets based on routing decisions, and hosts, machines that reside at 'the edge' of networks, either as a source of, or destination for, a packet.

Hosts and routers are connected by local networks called lines. There are various local network standards, with different properties. Some of these properties are of interest in a routing context, such as bandwidth, delay and load. These can be combined in a routing metric, used to order lines with respect to desirability in terms of transmission. By associating a metric to each line we can employ a routing algorithm to determine the optimal path between any source and destination.
There are various kinds of routing algorithms and we distinguish between static algorithms where the routing algorithm is performed only once and dynamic algorithms where the routing information is updated continuously to adapt to changes in the network topology. The most common routing algorithms are so-called link-state algorithms.

\section{B. Link State Routing}

Link state routing is based on the premise that all routers have knowledge of the entire topology of the network in which the algorithm operates. The operation of the algorithm is then concerned with gaining this knowledge, with updating it to adapt to changes, and with computing routing tables that are used for forwarding. More concretely, there are five tasks for each router.

1. Discover and identify neighbouring routers.

2. Measure the cost, in terms of the chosen metric, to each of one's neighbours.

3. Construct a packet containing the information from task 1 and 2.

4. Send the packet to all other routers on the network, and receive packets from all others.

5. Compute the shortest (lowest cost) path to every other router. This is possible because the packets contain all information necessary to learn the topology of the network. The computation of shortest paths is done with Dijkstra's algorithm [9].

The theory behind link-state algorithms is concretized in routing algorithm standards such as IS-IS[10] and OSPF[11].

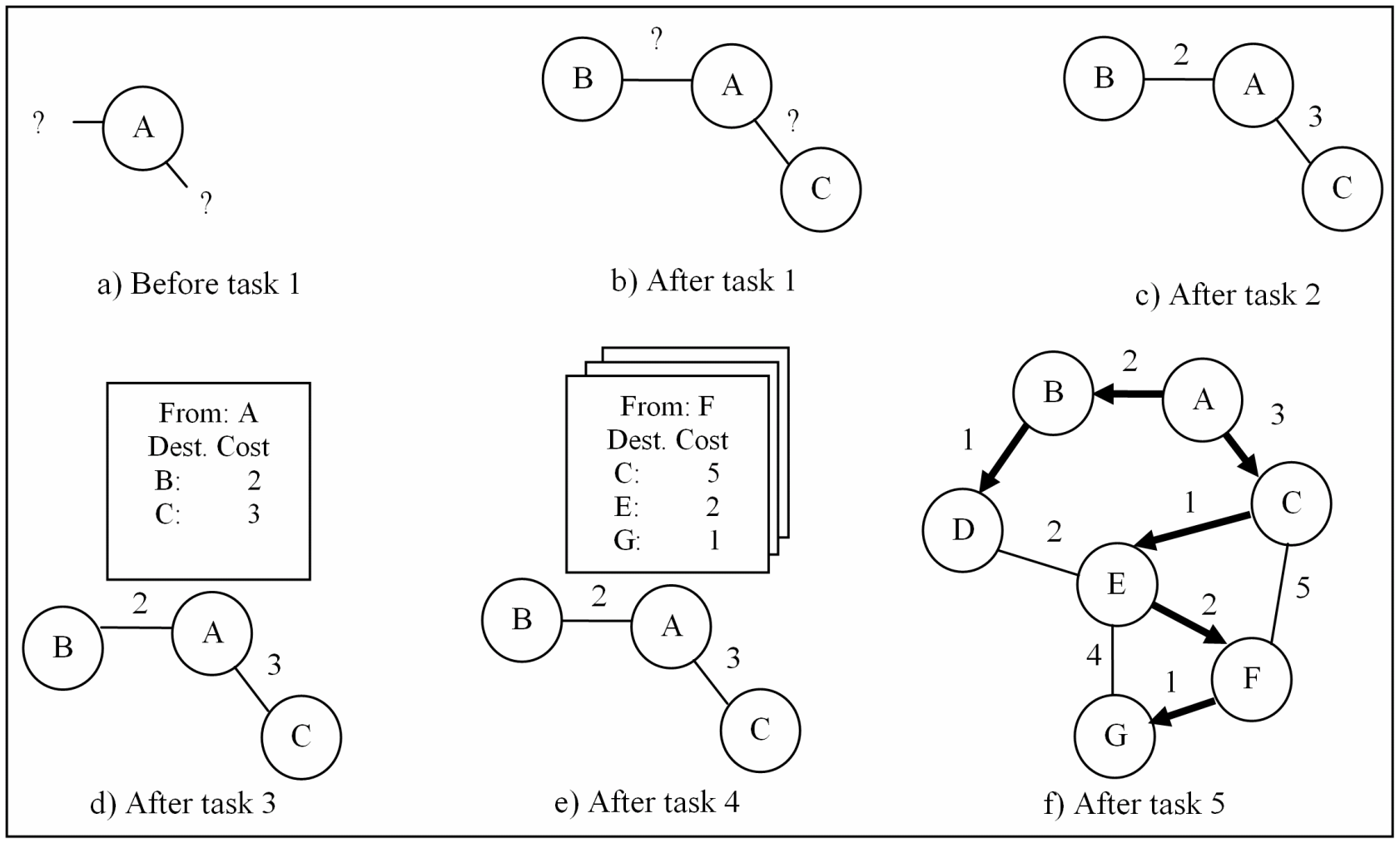

Figure 1. The process link state router A goes through, from the time it is booted, a), until it has knowledge of the entire network, and the shortest paths to each router. 


\section{A COMPuter Game Modelling Routing In COMPUTER Networks AS AbSTRACT LeARning Material IN A BLENDED LEARNING ENVIRONMENT}

\section{Modelling networks for routing}

The usual theoretical model used to represent a network for routing purposes, is that of a graph, directed or undirected. The hosts and routers are the vertices, the lines are edges, and each edge has the corresponding line's metric as cost. The model of a graph can also be applied, as it is in our game, to a maze: Intersections are vertices and corridors are (undirected) edges.

An edge cost that could function as an intuitive routing metric is the length of the corridors - the longer the corridor, the longer time the player has to run. This cost is explicitly given to the players as signposts at intersections. Routing information is gathered by traversing the maze, while forwarding is modeled by choosing a corridor when arriving at an intersection.

\section{GAME PLAY}

The game play in the prototype is simple, and combines routing and forwarding. Students start out in an area, marked start on the map. In this area there is a Non Player Character (NPC) that gives them quests to perform. These quests all consist of delivering a package (representing a 'data packet') to another NPC (host) somewhere. The students are neither told where the destination is located nor about the layout of the maze. The aim is to run to the NPCs location (simulating transmission of the data packet), and deliver the package to them. The NPC at this location will then hand the student another package for a second destination and so on.

All quests are made up of five such steps. When the final NPC of a quest gets their package the reward is one piece of gold, and an instruction to go back to the start for another quest. Gold are used to purchase items in the shop located at start in the maze. The items that can be purchased are different t-shirts and other items to customise the look of their avatar.

The game is built as a standard MMORPG but several features are disabled. The disabled features are things like map, tracking and all other navigational features.

Figure 3 shows the scene at the beginning where a student can select any one of a number of new quests. Previously started quests will automatically be removed from the list. A student is only permitted to start one quest at a time.

At the beginning of the game, the player will receive their first item, but must, since they have no knowledge of the maze layout, search blindly for the destination.

The picture in figure 4 shows the view that meets the student as he enters the first intersection. Three signposts (only two shown on picture) with information about what intersection can be found in which direction and how far it is. The distances indicated are correct for the avatar in the virtual world. The non real element is that the avatar is able to run fast over long distances with no drop in speed. Note that the only information that the student can use to navigate is the signposts, no other directional information is available.

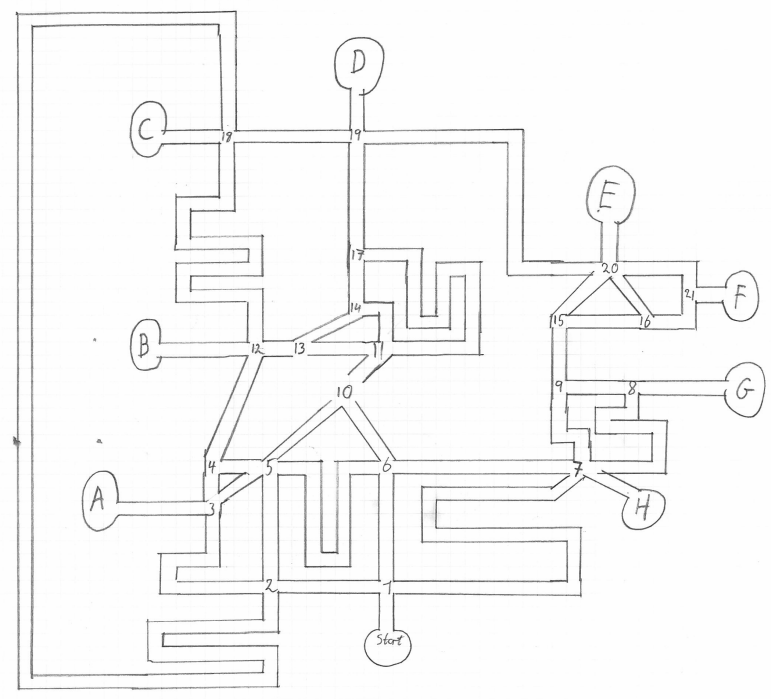

Figure 2. Map of the gaming area

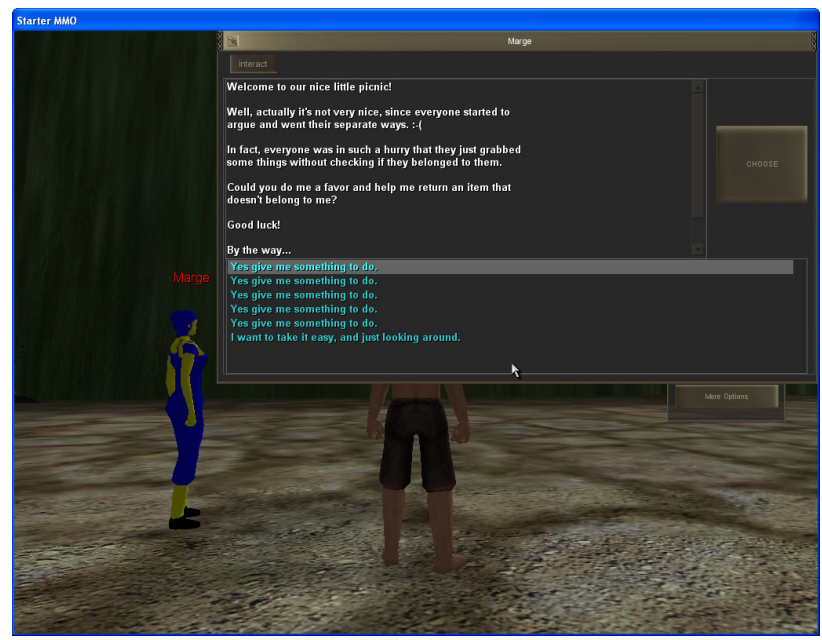

Figure 3. Starting out on a network quest

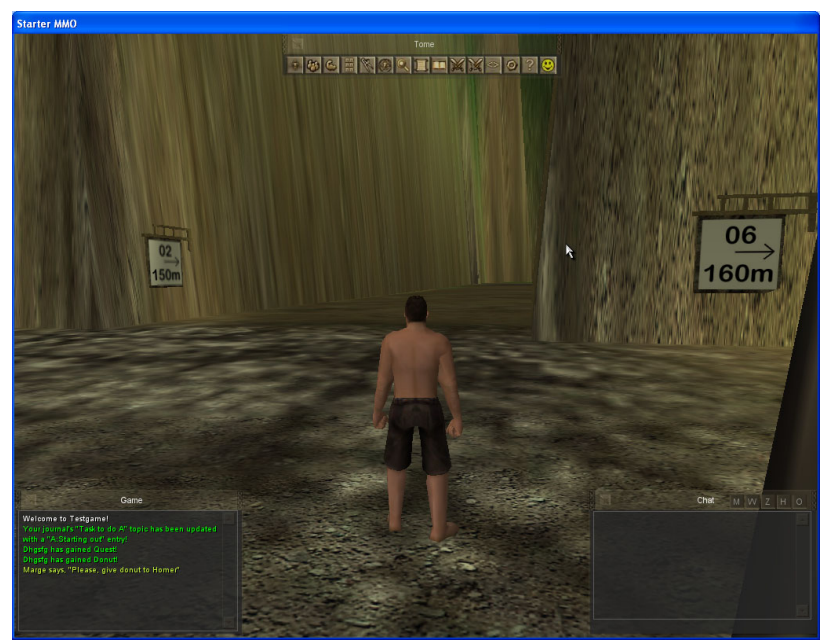

Figure 4. First intersection in the networking prototype 


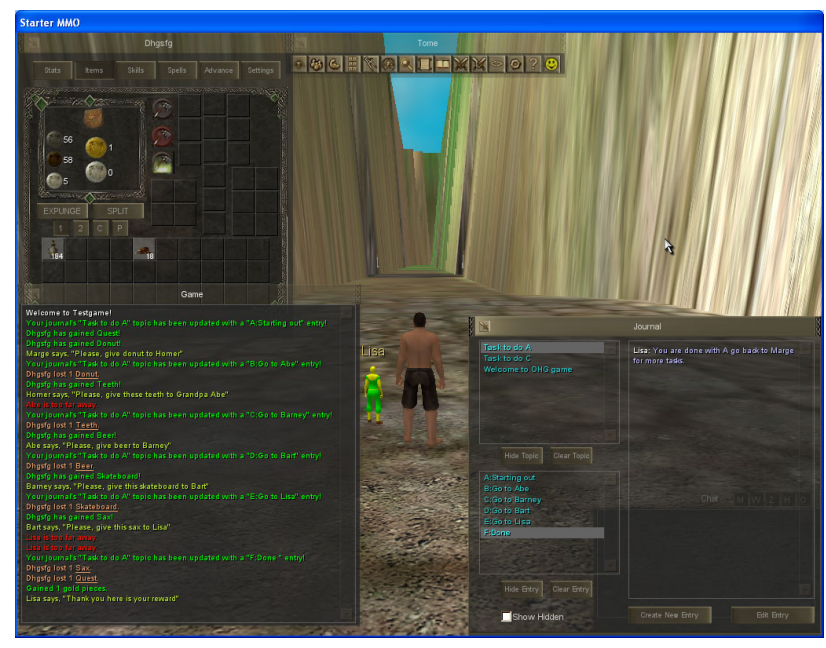

Figure 5. A quest is complete

Picture above shows a complete quest. The dialogue that has taken place is shown in the The "Game" window on the lower left and the automatically generated journal that the student can use at any time during the quest is shown on the right. The obscured window below the journal is the chat window that can be used by the participants at any time during the game to communicate with the other participants currently in the game.

\section{A. Link State Routing versus Game Play.}

In realizing the game we wanted there to be a correlation between the winning strategy and the steps of a link state routing algorithm - the students that wanted to play the game in the optimal way (and win!), would have to perform routing.

The main obstacle to achieving this goal was the difference in point of view between link state routing and the game: In routing the participating entities are the stationary routers, in the game the players are kind-of messages travelling the maze and gathering information.

Thus it was not possible to simulate the broadcasting of neighbour information performed during task 3 of link state routing. Instead, the players would slowly build up their knowledge of the network by performing the quests given to them. On the other hand the constant updating of the network topology worked as a simulation of changing topology: The players would constantly find new routes between NPCs.

The players used pen and paper to map the maze and help them in playing. This was a natural consequence of using distance as a metric - the main factor influencing the rate at which the players solved their quests. As the players discovered new intersections, paths and NPCS they would have to update their maps and also their paths.

Since the players did not perform Dikjstra's algorithm, but rather calculated paths by inspection and by mental arithmetic, there was no guarantee that players would use the shortest paths available to them. However we can assume (and indeed observed) that they at least used very good paths, which they calculated based on the maps they drew.

\section{TRIALS}

The trial was run in an ordinary classroom where students used a mix of standard PCs and their own laptops.
The game was preinstalled on the PCs, and in addition the students were free to download and install the client on their own computers. The lecturer also logged in and used a projector to show his view in large format for all to see. The students logged in and had about 10 minutes to familiarise themselves with the controls and options available in the game. Then the lecturer set the scene for the "game" to begin.

The lecturer had previously decided that the "game" would be a competition. The winner would be the participant who was able to buy a t-shirt from the shop and put it on first. The cost of a t-shirt meant that a participant had to complete a minimum of three quests to acquire the funds necessary.

All participants gathered together so they were in view on the main screen and the race was on. First they where guided to a group of cloned start quest NPCs, this gave all the participants an option to start simultaneously.

Though the system was available for the participants after the experiment, continued use of the game after the initial session were the game was run, was not part of the experiment and no statistics on reuse was saved.

\section{A. Results}

The experiment was run with 10 students. All the students filled in a questionnaire, detailing their familiarity with games, their attitudes before, and their impression after completing the experiment. All questions on the questionnaire is on a 5 point Likert scale (Very little; Not much; Average; Quite a lot; Lots).

The questions in the questionnaire are converted to numbers on a scale from 1 to 5 to create the average score in the table below.

TABLE I.

RESULTS OF THE STUDENT SURVEY

\begin{tabular}{|cc|}
\hline Question & $\begin{array}{c}\text { Average } \\
\text { score }\end{array}$ \\
\hline Do you enjoy playing computer games? & 4.2 \\
\hline Experience with games created for learning? & 1.6 \\
\hline Did playing improve your knowledge? & 2.9 \\
\hline Benefit compared to traditional lecture/lab? & 2.8 \\
\hline Did you enjoy the game? & 3.7 \\
\hline How useful are games like this for learning? & 3.7 \\
\hline Did you have any difficulty using the game? & 1.7 \\
\hline Did you have any difficulty navigating the \\
labyrinth?
\end{tabular}

In figure 6-9 are the details of the students' responses to the central questions for this investigation.

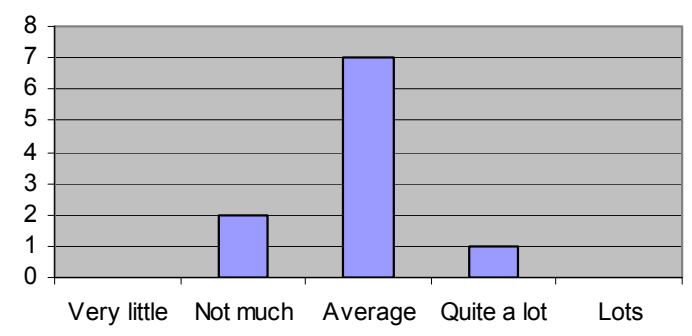

Figure 6. Did playing improve your knowledge 


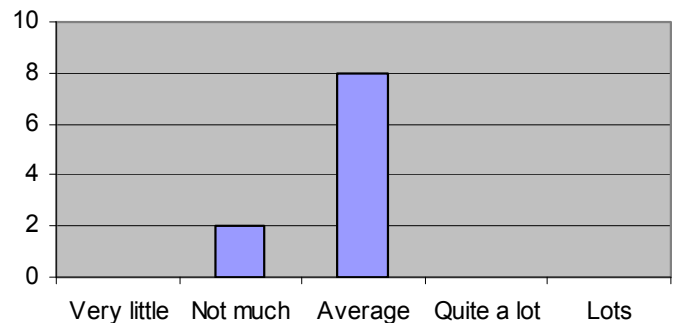

Figure 7. Benefit compared to traditional lecture/lab

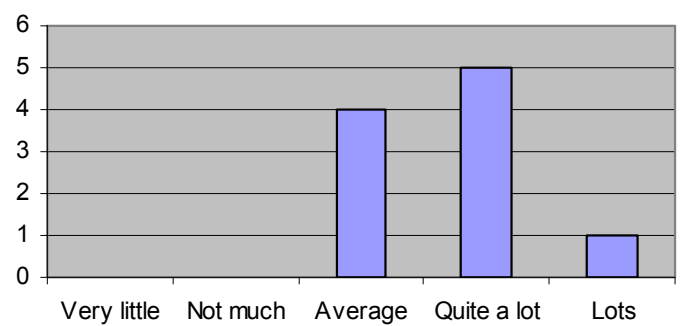

Figure 8. Did you enjoy the game

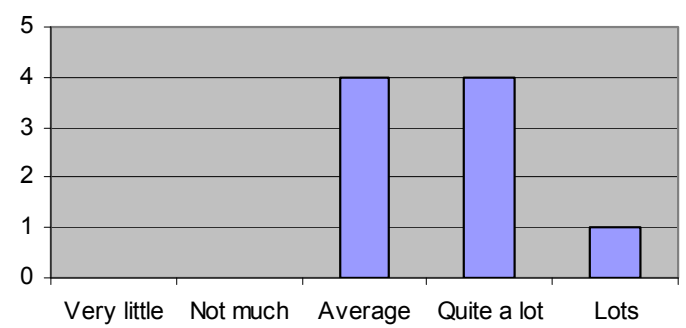

Figure 9. How useful are games like this for learning

In addition to the questions the participants were also given the option to comment. Of the few participants who took advantage of making a comment they wrote short statements in Norwegian, which translates into lines like: "nice idea", "fun" and "more of this".

\section{CONCLUSIONS}

The aim of this experiment is to show a prototype for a system that utilises games-based technology to support a blended learning environment. The prototype is designed to use no pure games elements but rather to focus on creating a virtual environment and storyline to support the learning activities. The modelling of the content in the game was developed as an abstraction of the learning topic focused on in the accompanying workshop.

The conclusions we may draw from the student feedback on the experiment is that overall the students felt that they learned just as much from this experiment as from a traditional lecture/lab, but that they enjoyed this more, which met the requirement from the lecturer of greater engagement and increased motivation for the topic. The experiment also demonstrated that games designed for specific learning purposes without additional game-play can be engaging and motivating for students. This is in keep with our other research which we have reported in [12-14] where we make use of game technologies as learning environments.

\section{REFERENCES}

[1] R. Motschnig-Pitrik and K. Mallich, "Effects of Person-Centered attitudes on professional and social competence in a blended learning paradigm," Educational Technology \& Society, vol. 7, pp. 176192, 2004.

[2] D. R. Garrison and H. Kanuka, "Blended learning: Uncovering its transformative potential in higher education," The internet and higher education, vol. 7, pp. 95-105, 2004. (doi:10.1016/i.ih educ.2004.02.001)

[3] R. Woods, J. D. Baker, and D. Hopper, "Hybrid structures: Faculty use and perception of web-based courseware as a supplement to face-to-face instruction," The internt and higher education, vol. 7, pp. 281-297, 2004.

[4] P. Herse and A. Lee, "Optometry and WebCT: a student survey of the value of web-based learning environments in optometric education," Clin Exp Optom, vol. 88, pp. 46-52, 2005.

[5] J. B. Biggs, Teaching for quality learning at university : what the student does, 2nd ed. Phildelphia, Pa.: Society for Research into Higher Education : Open University Press, 2003.

[6] J. T. Mayes, "Dialogue with a dumb terminal," in Times Higher Education Supplement October 10th, 1997.

[7] M. Khalifa and R. Lam, "Web-based Learning: Effects on learning process and outcome," IEEE Transaction on education, vol. 45, pp. 350-356, 2002. (doi:10.1109/TE.2002.804395)

[8] C. Huitema, Routing in the Internet, 2nd ed. Upper Saddle River, N.J.: Prentice Hall PTR, 2000.

[9] E. W. Dijkstra, "A note on two problems in connexion with graphs," Numerische Mathematik, vol. 1, pp. 269-271, 1959. (doi:10.1007/BF01386390)

[10] OSI IS-IS Intra-domain Routing Protocol http://tools.ietf.org/ html/rfc1142 Last visited 06 October 2009.

[11] OSPF for IPv6 http://tools.ietf.org/html/rfc5340 Last visited 06 October 2009.

[12] O. H. Graven and L. MacKinnon, "Prototyping Games-Based Environments for learning $\mathrm{C}++$ programming," presented at $\mathrm{HCI}$ Educators, Dundee, UK, 2009.

[13] O. H. Graven and L. M. MacKinnon, "Prototyping a Games-Based Environment for Learning," in eLearn. Las Vegas, US: AACE Press, 2008.

[14] O. H. Graven, D. Samuelsen, and L. M. MacKinnon, "Gamesbased environment for e-learning in analogue electronics," in ICL. Villach, Austria: International Associsiation of Online Engineers, 2008 .

\section{AUTHORS}

O. H. Graven is with Buskerud University College, Department of Technology, Postboks 251, 3601 Kongsberg, NORWAY (e-mail: Olaf.Hallan.Graven@ hibu.no).

H. A. Hansen is with Buskerud University College, Department of Technology, Postboks 251, 3601 Kongsberg, NORWAY (e-mail: Hallstein.Asheim.Hansen@ hibu.no).

L. M. MacKinnon is with Buskerud University College, Department of Technology, Postboks 251, 3601 Kongsberg, NORWAY (e-mail: Lachlan.MacKinnon@ hibu.no) and with University of Abertay Dundee, Scotland, UK.

This article was modified from a presentation at the International Conference of Interactive Computer Aided Learning ICL2009, September 2009 in Villach, Austria. Submitted 06 October 2009. Published as resubmitted by the authors on 2 November 2009 . 